\title{
Rapid analysis of pregnanediol in pregnancy urine
}

\author{
W. COOPER, M. G. COYLE, AND V. K. SMITH ${ }^{1}$ \\ From the Department of Obstetrics and Gynaecology, University of Dundee, Dundee
}

SYNOPSIS A simple, inexpensive, and rapid method for the determination of pregnanediol in pregnancy urine by gas liquid chromatography is described. Automatic injection of the samples into the gas chromatograph allows up to 36 samples to be run overnight thus saving valuable technical time.

The method described can easily be adopted for use in a routine steroid laboratory. The results obtained by this method have been compared with values obtained by the method of Klopper, Michie, and Brown (1955).

Urinary pregnanediol excretion in late pregnancy has been used for many years as an index of placental function (Coyle, Mitchell, and Russell, 1956; Russell, Paine, Coyle, and Dewhurst, 1958; Shearman, 1959). These workers used the method of Klopper et al (1955) which can be adopted for routine laboratory use but it is expensive in chemicals, requires skilled technical handling, and is time consuming.

A method was described by Podmore (1966) for routine determination of pregnanediol using a gas chromatograph with automatic application of samples. The commercial availability of an automatic device (Ruchelman, 1966; Jenkins and Hunt, 1968) for the application of samples to the gas chromatographic column and the development of gas chromatography methods for analysis of pregnanediol in urine have made this assay more readily available for clinical assessment of placental function.

Gas-liquid chromatographic methods for the estimation of pregnanediol in urine have been adequately reviewed (van der Molen, 1968).

However, many of the publications relating to these techniques were in reality feasibility studies for they failed to evaluate their performance in actual use. Some workers (Goldzieher, Mattijssen, Gual, Vela, and De La Pena, 1967; Scommegna, Chattoraj, and Wotiz, 1967) have reported that a team of three technicians can perform 200 pregnanediol determinations in a five-day week from receipt of the urine to reporting the result. This was achieved without the use of an automatic sample

'Present address: Departmer.t of Chemical Pathology, St Mary's Hospital Medical School, St Mary's Hospital, London

Received for publication 18 August 1972. injector. More recently, Barrett and Brown (1970) have adapted the method of Cox (1968) using a semiautomatic extractor for processing the urine. They obtained excellent agreement between the results of this method and the results obtained using the procedure of Klopper et al (1955) apart from an apparent overestimate of approximately $0.6 \mathrm{mg} / 24 \mathrm{~h}$ in Klopper's estimate of follicular phase levels.

The present investigation was undertaken to evaluate various gas chromatographic techniques, convenient methods for hydrolysis, and to formulate a simple method for the routine laboratory using an automatic solids injector system.

\section{Materials and Apparatus}

Complete 24-h urine specimens obtained from women whose gestation period varied between 10 and 40 weeks were analysed within a few hours of completion of the collection.

The completeness of collection was checked by measurement of urinary creatinine (Wray and Russell, 1960).

All reagents used in the assay were of AR grade and all volatile solvents were distilled before use except toluene (sulphur free) which was used as purchased. The enzyme preparation ( $\beta$-glucuronidase and sulphatase) was prepared according to Dodgson and Spencer (1953) and assayed by the method of Talalay, Fishman, and Huggins (1946). Alumina (MacArthys Ltd) was deactivated by the addition of approximately $10 \%$ water. All steroids used were the products of Sigma (London) Chemical Co Ltd or were a gift from Professor Klyne (MRC 
Steroid Reference Collection). Their homogeneity was checked by thin-layer chromatography and gasliquid chromatography before use. Progesterone, used as an internal standard, was repeatedly crystallized from ethyl acetate-hexane till the melting point remained constant $\left(129^{\circ} \mathrm{C}\right)$.

The Pye series 104 model 4 gas chromatograph equipped with a hydrogen flame ionization detector was used in this study. Initially, a closed injection system which allowed manual introduction of solid samples into the injection heater zone of the column was used (Bailey, 1967). However, this method could not be adopted for automatic injection and the method finally chosen allowed samples to be introduced in a solid state on Dixon gauze rings $1.58 \times 1.58 \mathrm{~mm}$ (Ruchelman, 1966).

\section{Methods}

The investigation was undertaken in three parts and in each the results obtained for the gas liquid chromatographic technique were compared with those determined by the method of Klopper et al (1955), which is the standard method used in most routine laboratories. Duplicate samples of urine were used throughout this study. The technique for acid hydrolysis was that of Klopper et al (1955). Enzyme hydrolysis was achieved by adjusting the urine

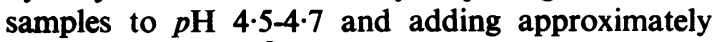
1000 units $/ \mathrm{ml}$ of $\beta$-glucuronidase/sulphatase, $5 \mathrm{ml}$ $1 \mathrm{M}$ sodium phosphate buffer solution $p \mathrm{H} 4 \cdot 6$, and incubating for $48 \mathrm{~h}$ at $37^{\circ} \mathrm{C}$.

The final stage of the Klopper method is a colour reaction between sulphuric acid and pregnanediol diacetate. Colour densities are read on a spectrophotometer at $430 \mathrm{~m} \mu$ after $17 \mathrm{~h}$ incubation. However, in this laboratory the colour densities are read after one hour's incubation for speed in reporting urgent specimens. In order to assess any error produced by reading at one $h$, the colour densities of the residues after final chromatography of 15 samples of urine were measured at $430 \mathrm{~m} \mu$ after one $h$ and a 17-h incubation with sulphuric acid and separate standard curves was prepared. No significant difference was observed between the accuracy of measurement using a one-h or a $17-\mathrm{h}$ incubation. The mean level of pregnanediol found was $21 \cdot 1 \pm 11 \cdot 3$ $\mathrm{mg} / 24 \mathrm{~h}$ for the one-h incubation and $21 \cdot 2 \pm 11 \cdot 13$ $\mathrm{mg} / 24 \mathrm{~h}$ after $17 \mathrm{~h}$-incubation.

There are, however, non-specific chromogenic impurities in urinary extracts which may make a correction factor necessary, unless the compounds being measured are present in considerable amounts. To investigate this point, the colour densities of 15 final residues were measured at 380,420 , and $460 \mathrm{~m} \mu$ after one-h and 17-h incubation and an Allen correction was applied (Allen, 1950). There was no significant difference between the uncorrected and corrected values for the one-h and 17-h incubation.

After one-h incubation the mean level of pregnanediol estimated at $430 \mathrm{~m} \mu$ was $21 \cdot 1 \pm 11 \cdot 3$ $\mathrm{mg} / 24 \mathrm{~h}$ and $18.9 \pm 11.4 \mathrm{mg} / 24 \mathrm{~h}$ using the Allen correction. After a 17-h incubation it was $21 \cdot 2 \pm 11 \cdot 13$ $\mathrm{mg} / 24 \mathrm{~h}$ uncorrected and $20 \cdot 1 \pm 11.0 \mathrm{mg} / 24 \mathrm{~h}$ when Allen corrected.

These findings would suggest that a single reading क at $430 \mathrm{~m} \mu$ after incubation for one hour is reliable $\vec{\circ}$ for the levels found in pregnancy.

\section{SERIES 1}

In the method of Klopper et al (1955) the urine is hydrolysed by boiling with concentrated hydro- in chloric acid. It has been reported by some workers (Patti, Bonnano, Frawley, and Stein, 1963; Guarnieri and Barry, 1968; Vela, Acevado, and Campbell, 1969) that this method of hydrolysis destroys as much as 10 to $30 \%$ of the pregnanediol present in the urine. In order to establish the best conditions for hydrolysis of pregnanediol glucosiduronate in urine, a comparison of acid and enzyme hydrolysis on the same sample of urine was made. In this series, 19 samples of pregnancy urine were subjected to acid or enzyme hydrolysis. After first column chromato $\overrightarrow{0}$ graphy (Klopper et al, 1955) the eluates were collected and divided equally. In one case the eluat were evaporated to dryness, acetylated, an measured using gas liquid chromatography. The remainder were subjected to the full procedure of Klopper et al (1955) and measured colorimetrically at a single wavelength $(430 \mathrm{~m} \mu$ ).

SERIES 2

Since the inclusion of alumina chromatography is a time-consuming operation, further studies were made in which the crude toluene extract obtained after acid hydrolysis was extracted with $\mathbf{N}$ sodium hydroxide. The alkaline layer was discarded and the toluene layer was washed with distilled water and evaporated to dryness. The dried residue was acetylated and subjected to gas liquid chromatography as before. In this series of experiments 65 samples of pregnancy urine were analysed by the shortened method and also by the colorimetric method of Klopper et al (1955).

SERIES 3

A more rapid and convenient gas liquid chromatography procedure was desired. Therefore, a modification of the method of Podmore (1966) was used $\stackrel{O}{工}$ and a comparison was made between this shortened procedure and the method of Klopper et al (1955). There were 75 samples of pregnancy urine in this series. A flow chart for all series is shown in Figure 1. 


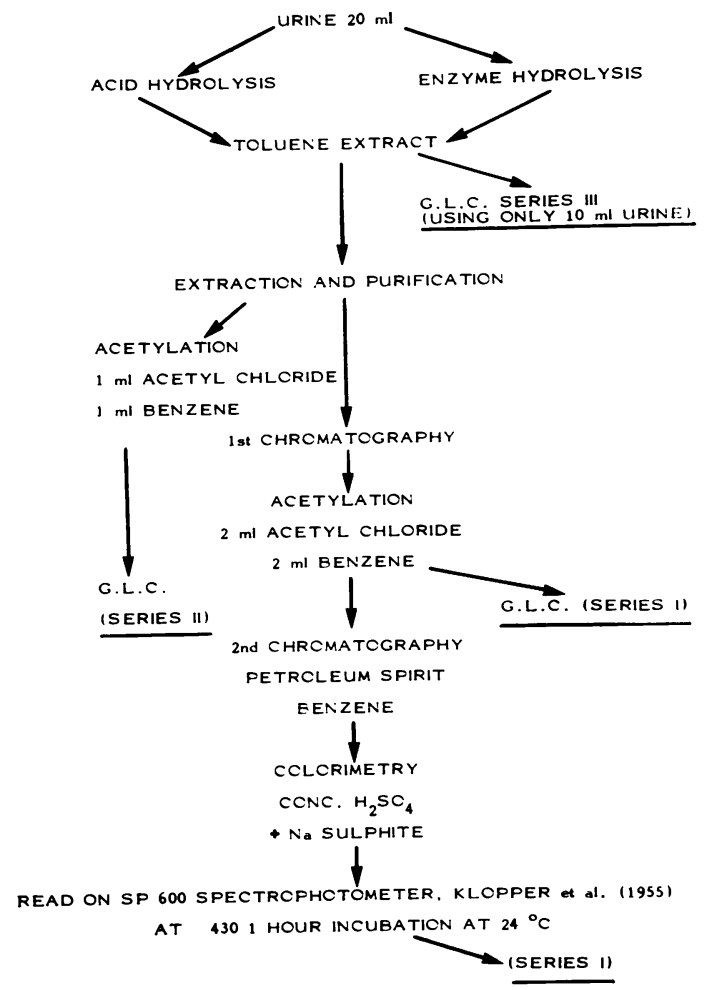

Fig. 1 Extraction of pregnanediol from pregnancy urine (all series).

THE METHOD FOR SERIES 3 IN DETAIL Hydrolysis and extraction

Twenty-four samples of urine were processed at one time. A 5- or 10-ml portion of a $24-\mathrm{h}$ urine sample was transferred to a test tube, concentrated $\mathrm{HCl}$ $(1.5 \mathrm{ml})$ was added, and the mixture was placed in a boiling water bath for 12 minutes. After cooling, toluene $(10 \mathrm{ml})$ was added to the mixture and the tube stoppered and mechanically shaken for 10 minutes. The layers were separated by adding 3 drops of Johnston's wetting agent, shaking the mixture gently, and allowing it to stand for five minutes. Centrifugation was not necessary. An aliquot of toluene extract $(5 \mathrm{ml})$ was transferred to a small test tube and evaporated under a stream of dry nitrogen at $60^{\circ} \mathrm{C}$.

\section{Acetylation}

To the dried residue was added benzene $(1 \mathrm{ml})$ and acetylchloride $(1 \mathrm{ml})$. The mixture was allowed to stand at room temperature for one $h$ and the excess solvent was evaporated under a stream of nitrogen.
Gas chromatography

The dried acetylated compound was dissolved in ethylene dichloride containing progesterone (200 $\mu \mathrm{g} / \mathrm{ml})$ as an internal standard. Dilution was varied according to the expected amount of pregnanediol.

\section{Sample preparation and injection technique}

Samples were introduced into the gas chromatograph on Dixon (stainless steel) gauze rings $1.58 \mathrm{~mm} \times 1.58$ mm (Griffith \& George Ltd, Middlesex) which had been previously cleaned by soxhlet extraction, for one $h$ with ethylene dichloride.

The gauzes were placed in the concavities of a teflon evaporating plate (Menini and Norymberski, 1965) and $10 \mu \mathrm{l}$ of the sample in the presence of an internal standard was dropped onto the wire gauze using a Drummond microcap.

The solvent was evaporated using the heat generated from a small electric light bulb (Microlite, A. Gallenkamp Ltd). If necessary additional aliquots of the sample could be added, to increase the percentage of sample used for the analysis. The charged gauzes were picked up with teflon-tipped tweezers and placed into the slots of the teflon-lined wheel of the injector and the system was sealed to the atmosphere by replacing the wheel cover.

\section{Operating conditions}

Gas liquid chromatography was carried out under isothermal conditions using a Pye series 104 model gas chromatograph fitted with an auto solids injector (Ruchelman, 1966). A (1.5 m) glass column with an internal diameter of $3.5 \mathrm{~mm}$ was used and the detector end of the column was fitted with a sintered glass disk in place of siliconized glass wool plug. The column was packed with $3 \%$ XE 60 on Gas-Chrom Q, 100-120 mesh (Applied Science Laboratories). The oven and detector temperature were maintained at $230^{\circ} \mathrm{C}$. The injection heater temperature was $280^{\circ} \mathrm{C}$; attenuation $2 \times 10^{-9} \mathrm{~A}$ and $1 \times 10^{-9} \mathrm{~A}$ depending on the amount of steroid present. Argon was used as a carrier gas at flow rate of $45 \mathrm{ml} / \mathrm{min}$.

\section{Measurement}

Using the internal standardization procedure, known weight ratios of $5 \beta$ pregnane-3a, 20a diol diacetate and progesterone (internal standard) were prepared and chromatographed at the same time as the urine samples were being analysed. The resultant peak areas were measured and the component : internal standard area ratios obtained were plotted against the component : internal standard weight ratios and these gave a curve which was linear for the values obtained in pregnancy, ie, 50-250 $\mu \mathrm{g}$. The pregnanediol content of the unknown was calculated by 
RREG;

"BEGIN" "INTEGER" NO, WK, J, N;

"REAL" H, W, CH, CW, R;

"IFTEGER" "ARRAY" A[12:42, 1:2];
Fig. 2. ALGOL programme for urinary pregnanediol assay.

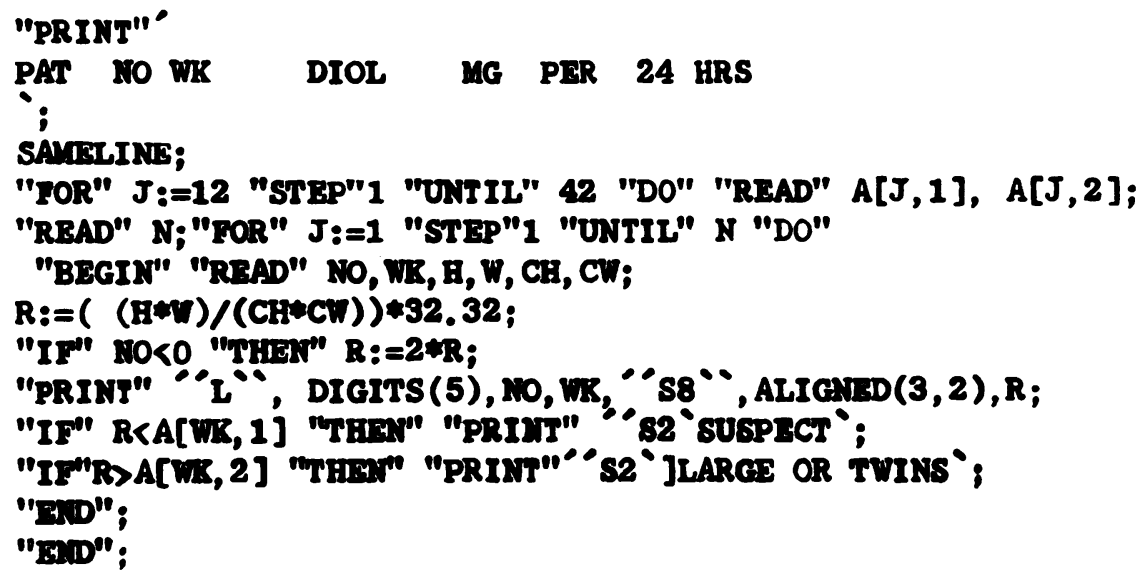

PAT NO WK

$\begin{array}{rr}-50 & 35 \\ -51 & 35 \\ -52 & 38 \\ -53 & 38 \\ 56 & 34 \\ -58 & 39 \\ 59 & 34 \\ 61 & 32 \\ 62 & 32 \\ -63 & 38 \\ -64 & 38 \\ -66 & 40 \\ 67 & 30 \\ 68 & 30 \\ 69 & 25 \\ 70 & 25 \\ -71 & 39 \\ -72 & 39 \\ -73 & 39 \\ 74 & 38 \\ 75 & 37 \\ -76 & 37\end{array}$

DIOL MG PER 24 HRS

$31 \cdot 34$

$32 \cdot 12$

43.61

47.96

30.09

88.41

$45 \cdot 98$

$24 \cdot 19$

25.03

47.06

50.11

33.93

$46 \cdot 31$

$49 \cdot 15$

$30 \cdot 31$

$29 \cdot 78$

44.61

$25 \cdot 95$

24.76

$46 \cdot 16$

$32 \cdot 12$

SUSPECT

SUSPECT

$31 \cdot 85$
LARGE OR TWINS

Fig. 3. Computer printout from ALGOL programme

multiplying by 0.8 (the ratio of the molecular weights).

\section{Computer analysis}

The use of an auto injector enables up to 36 samples to be run overnight. Therefore, many more extracts can be processed in one day. However, time and effort are still spent measuring the areas by triag- $\vec{\theta}$ gulation and the retention times of the eluted peak. ? Since the services of a computer were made readifif available to us at no extra cost it was decided to uș it to increase the speed and precision of the assay.

It was still necessary to make some measurements of the peaks and the retention times but measurements were recorded directly onto punch tape or $\overrightarrow{\vec{P}}$ card.

The computer program

The program was written in ALGOL for an Elliot 4120 computer (Fig. 2.) which then processed? the following information. The patient's number, weeks of gestation, and data obtained from gas: liquid chromatography measurements. The com-윽 puted component:internal standard area ratios obtained were multiplied by 32.32 (the slope of the 궁 calibration curve). If the dilution of the sample had $>$ been altered, eg, $\times 2$, then a minus sign was included with the patient's number thus instructing the N computer to multiply the final result by 2 . Other parameters were added on a separate data-punched 0 tape to give a mean lower range and higher range for $\omega$ normal pregnancy based on results obtained from this laboratory. If the final result fell below the lower range, the computer was instructed to print $\Phi$ 'suspect' as this was highly significant. For results' obtained above the mean for large babies the printout read 'large or twins' (Fig. 3). 
Results

SER IES 1

Statistical comparison between acid and enzyme hydrolysed samples of 19 pregnancy urines revealed a mean difference of $1.69 \mathrm{mg} / 24 \mathrm{~h}$ for the method of Klopper et al (1955) and $1.36 \mathrm{mg} / 24 \mathrm{~h}$ for the gas liquid chromatography method. The differences were insignificant $(P>0 \cdot 2)$. It was concluded from these analyses that acid or enzyme hydrolysis gave comparable results using either the method of Klopper et al (1955) or gas liquid chromatography procedure and that in future experimental comparisons acid hydrolysis would be used as it was less time consuming and inexpensive in use. Using acid hydrolysis the precision of the gas liquid chromatography method was found to be $\pm 0.7 \mathrm{mg} / 24 \mathrm{~h}$ (SD) and $\pm 1.1 \mathrm{mg} / 24 \mathrm{~h}$ (SD) for the method of Klopper et al (1955) at a mean level of $14 \mathrm{mg} / 24 \mathrm{~h}$. Comparison of the individual results obtained with the two methods showed a mean difference of 2.05 $\mathrm{mg} / 24 \mathrm{~h}$ which was insignificant $(0.2<\mathrm{P}<0.4)$.

SERIES ?

Comparison of the results obtained with the two methods employed revealed a mean difference of $1.66 \mathrm{mg} / 24 \mathrm{~h}$ which was insignificant $(\mathrm{P}>0.5)$. When the precision of the methods was tested by statistical analysis of the differences between duplicate determinations (Snedecor, 1952) it was found that there was an unimportant error in duplication of results by either method. From 65 pairs of duplicates with a mean pregnanediol concentration of $17.0 \mathrm{mg} / 24 \mathrm{~h}$ a standard deviation of $\pm 1.37 \mathrm{mg} / 24 \mathrm{~h}$ (SD) was obtained using the method of Klopper et al (1955) and $\pm 1.36 \mathrm{mg} / 24 \mathrm{~h}$ (SD) using the gas liquid chromatography method.

\section{SERIES 3}

In this series all of the samples obtained by the method of Klopper et al (1955) were read at a single wavelength $(430 \mathrm{~m} \mu)$ and, in order to increase specificity, they were also measured by reading at wavelengths 380,420 , and $460 \mathrm{~m} \mu$, and a correction factor (Allen, 1950) was applied.

Comparison of the results obtained with these two methods gave a mean difference of $2 \cdot 13 \mathrm{mg} / 24 \mathrm{~h}$. For all practical purposes this difference was insignificant $(0.4<P<0.5)$. Therefore the final comparison was made between a single reading at $430 \mathrm{~m} \mu$ (Klopper et al, 1955) and the gas liquid chromatography method (Podmore, 1966).

A final comparison between the chemical method and the gas liquid chromatography method revealed a mean difference of $1.55 \mathrm{mg} / 24 \mathrm{~h}$ which was not significant $(P>0.5)$. The precision obtained with this short gas liquid chromatography procedure using the method of Snedecor (1952) was \pm 1.62 $\mathrm{mg} / 24 \mathrm{~h}$ (SD) for 75 pairs of duplicates with a mean concentration of $34.9 \mathrm{mg} / 24 \mathrm{~h}$.

\section{Specificity}

Although the toluene extract is impure, no interference of the pregnanediol diacetate peak was observed (Fig. 4). Gas chromatography of the final residue gave in all cases a peak with an identical retention time to that of the authentic standard when the following phases were employed -XE 60, OV 17, and SE 30. The addition of authentic material to the extracts produced in each case increase in peak size without change in peak symmetry. It was found that pregnanediol diacetate was separated from allopregnanediol diacetate, other isomers of pregnanediol and its related metabolic products (Fig. 5 and Fig. 6).

Further evidence of identification was obtained by submitting the final residue to gas chromatographymass spectrometric analysis. The result of this

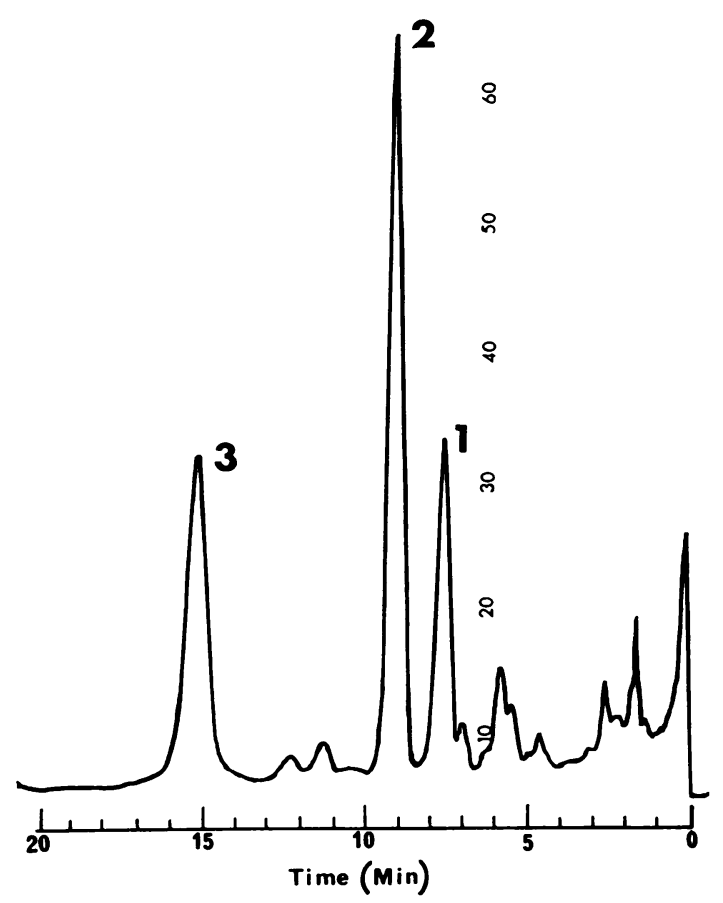

Fig. 4 Gas-liquid chromatography on $3 \%$ XE 60 at $230^{\circ} \mathrm{C}$ of toluene extract showing a separation of pregnanolone (1), pregnanediol diacetate (2), and progesterone (3) (internal standard). 


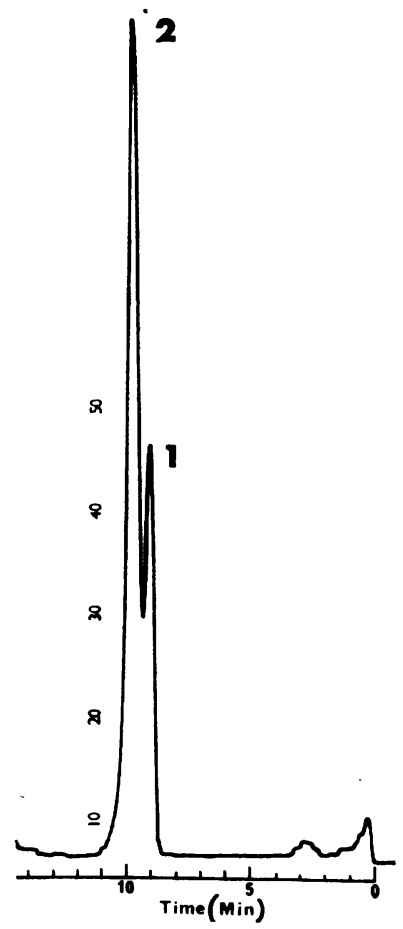

Fig. 5.

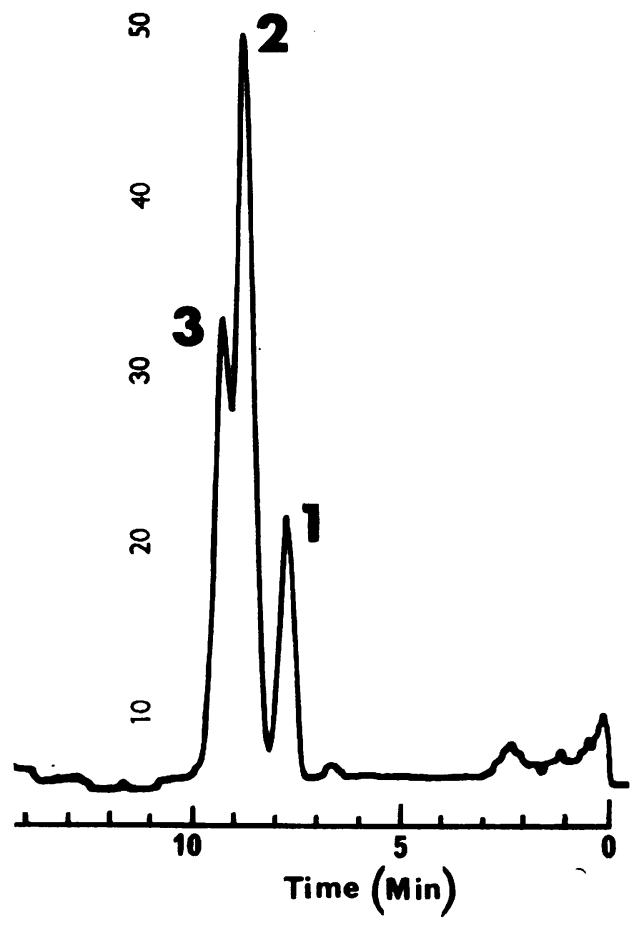

Fig. 6.
Fig. 5 Separation of 5B-pregnan-3a, 20a-diol diacetate (1) and 5a-pregnan-3a, 20a-diol diacetate (2) on $3 \% X E$ 60 at $230^{\circ} \mathrm{C}$.

Fig. 6 Separation of $5 \beta$-pregnan-3 $\beta$-ol-20-one acetate (1), 5B-pregnan$3 a, 20 \beta$-diol diacetate (2) and 5 -pregnan-3a, 20adiol diacetate (3) on $3 \%$ $X E 60$ at $230^{\circ} \mathrm{C}$. analysis was that the peak in the extract corresponding to pregnanediol diacetate gave a satisfactory mass spectrum apparently uncontaminated by closely related steroids. The distinction between stereoisomers, which would give similar spectra, has been covered by the gas liquid chromatography runs on various phases.

\section{Recovery}

In recovery experiments in which unconjugated pregnanediol $(50 \mu \mathrm{g})$ was added (before hydrolysis) to $10 \mathrm{ml}$ of early pregnancy urine, 20 replicate estimations gave a mean recovery of $87 \pm 7$ (SD) \% for the technique of Klopper et al (1955) and $97 \pm 9 \%$ for the gas liquid chromatography method used in series 3 .

Other recovery experiments (20) were performed in which $\left(1,2-{ }^{3} \mathrm{H}\right)$ pregnanediol was added to urine and the analysis done; the recovery of radioactivity in the final residue averaged $84 \pm 2.94 \%$ SD.

As this range was narrow and acceptable the results were not corrected for losses and they agreed with those reported by Cox (1968) and by other workers using gas liquid chromatography. Therefore, the use of a radioactive monitor on each individual specimen was thought to be unnecessary.

\section{Discussion}

It has been reported that pregnanediol is destroyed by acid hydrolysis and that enzyme hydrolysis prevents this destruction as well as giving further purification of the toluene extract (Vela et al, 1969). It was demonstrated by Klopper et al (1955), who made a detailed study of hydrolysis conditions for urine, that destruction did not take place if the instructions given in the method were strictly adhered to.

When a comparison was made between acid and enzyme hydrolysis using the method of Klopper et al $\mathrm{O}$ (1955) and a modification of the gas liquid chromatography procedure of Podmore (1966), insignificant 은 differences were found in the total amount of pregnanediol present in pregnancy urine.

Recovery experiments in which pregnanediol $(50 \mu \mathrm{g})$ was added to pregnancy urine showed that 0 using the gas liquid chromatography procedure the $N$ mean recovery values were slightly higher than those $N$ obtained by the method of Klopper et al (1955). O This may be accounted for by the losses on the alumina chromatographic columns used in the $\frac{\mathscr{\Phi}}{\Phi}$ method of Klopper et al (1955) which are approxi- $\stackrel{\oplus}{+}$ mately $5-10 \%$ when pure standards are applied to 7 the column. 
In all three gas liquid chromatography methods the values were always slightly higher when compared with those obtained by the method of Klopper et al (1955) but the differences were seldom greater than the overall error for duplicate analysis.

Preliminary experiments have shown that it is possible using the method described for series 3 to measure pregnanediol and pregnanolone simultaneously. In recovery experiments in which $50 \mu \mathrm{g}$ of unconjugated pregnanolone was added before hydrolysis to $10 \mathrm{ml}$ of early pregnancy urine 10 replicate samples gave a mean recovery of $88.4 \pm$ $7 \cdot 2 \%$. Since samples of sodium pregnanolone glucosiduronate could not be obtained, evaluation of the recovery of added conjugate was not possible. The peak which appeared in the pregnanolone monoacetate area had a retention time identical to that of the authentic material when run on SE30, OV 17, and XE 60.

The final residue was submitted to gas chromatography-mass spectrometry. The results of this analysis were unsatisfactory due to the low concentration of the steroid relative to contaminating material.

The amounts of pregnanolone originating from $5 \beta$ pregnane-3a-17a, 20a triol as a result of acid hydrolysis are normally too small to interfere with the routine determination of pregnanolone in urine (van der Molen, 1962).

The gas liquid chromatography method described in series 3 can easily be adopted for use in a routine laboratory and one technician can process 36 specimens of pregnancy urine in a working day. The extraction and evaporation processes take approximately four hours and the gas chromatograph can be loaded and run overnight. Using the computer program described, the results should be available for reporting by noon the following day.

We wish to thank Professor James Walker and Professor V. H. T. James for help and advice, and $\mathrm{Mr}$ A. Olsen for valuable technical assistance.

We are indebted to Dr C. J. W. Brooks of the Chemistry Department, Glasgow University, for performing mass spectrometry of the compounds, to Dr H. Braunsberg, CERU, MRC, Edinburgh, for kindly supplying us with the $\left(1,2-^{3} \mathrm{H}\right)$ pregnanediol, and to Professor W. Klyne, MRC Steroid Reference Collection, for supplying pure steroids.

\section{References}

Allen, W. M. (1950). A simple method for analyzing complicated absorption curves, of use in the colorimetric determination of urinary steroids. J. clin. Endocr., 10, 71-83.

Bailey, E. (1969). The estimation of cortisol, prednisolone and some of their unconjugated metabolites in biological fluids using gas liquid chromatography. In Gas Liquid Chromatography of Steroids, (Memoirs of the Society for Endocrinology, No. 16), edited by J. K. Grant, pp. 183-197, Cambridge University Press, London.

Barrett, S. A., and Brown, J. B. (1970). An evaluation of the method of Cox for the rapid analysis of pregnanediol in urine by gasliquid chromatography. J. Endocr., 47, 471-480.

Cox, R. I. (1968). The rapid analysis of pregnanediol as the free steroid. In Chromatographie en Phase Gazeuse des Steroids Hormonaux, edited by R. Scholler and M. F. Jayle, pp. 309-320. Dunod, Paris. Gordon and Breach, New York.

Coyle, M. G., Mitchell, F. L., and Russell, C. G. (1956. A report on a chromatographic assay of urinary pregnanediol in pregnancy. J. Obstet. Gynaec. Brit. Cwlth, 4, 560-566.

Dodgson, K. S., and Spencer, B. (1953). Studies on sulphatases. 4. Arylsulphatase and $\beta$-glucuronidase concentrates from limpets. Biochem. J., 55, 315-320.

Goldzieher, J. W., Matthijssen, C., Gual, C., Vela, B. A., and De La Pena, A. (1967). A simplified gas chromatographic method for large numbers of urinary pregnanediol determinations. Amer. J. Obstet. Gynec., 98, 759-766.

Guarnieri, M., and Barry, R. D. (1968). Simultaneous determination of pregnanediol and pregnanolone in urinary extracts by gas chromatography. Clin. Chem., 14, 35-37.

Jenkins, A., and Hunt, R. J. (1968). In Pye Unicam Chromatography Bulletin, edited by D. Barnes, 2(4), pp. 2-4.

Klopper, A., Michie, E. A., and Brown, J. B. (1955). A method for the determination of urinary pregnanediol. J. Endocr., 12, 209-219.

Menini, E., and Norymberski, J. K. (1965). An approach to the systematic analysis of urinary steroids. Biochem. J., 95, 1-16.

Molen, H. J. van der (1962). 5B-pregnan-3a-0L-20-one in urine. Acta endocr. (Kbh.), 41, 247-258.

Molen, H. J. van der (1968). Gas phase chromatography of progesterone and related steroids. In Gas Phase Chromatography of Steroids, edited by K. B. Eik-Nes and E. C. Horning, pp. 150-235. Springer, Berlin.

Patti, A., Bonnano, P., Frawley, T. F., and Stein, A. A. (1963). Gas-phase chromatography in separation and identification of pregnanediol in urine and blood of pregnant women. Obstet. and Gynec., 21, 302-307.

Podmore, D. A. (1966). Routine determination of urinary pregnanediol using a gas chromatograph with automatic sample application. J. clin. Path., 19, 619-621.

Ruchelman, M. W. (1966). Automatic solid injection system. J. gas Chromat., 4, 265-268.

Russell, C. S., Paine, C. B., Coyle, M. G., and Dewhurst, C. J. (1958). The pregnanediol excretion in normal and abnormal pregnancy. J. Obstet. Gynaec. Brit. Cwlth, 64, 649-672.

Scommegna, A., Chattoraj, S. C., and Wotiz, H. H. (1967). The clinical application of a gas chromatographic method for the routine determination of urinary pregnanediol. Fertil. Steril., 18, 257-271.

Shearman, R. P. (1959). Some aspects of the urinary excretion of pregnanediol in pregnancy. J. Obstet. Gynaec. Brit. Emp., 66, $1-11$.

Snedecor, G. W. (1952). Query no. 92. Biometrics, 8, 85-86.

Talalay, P., Fishman, W. H., and Huggins, C. (1946). Chromogenic substrates. 11. Phenolphthalein glucuronic acid as substrate for the assay of glucuronidase activity. J. biol. Chem., 166, 757-772.

Vela, B. A., Acevedo, H. F., and Campbell, E. A. (1969). Simultaneous determination of urinary pregnanolone, pregnanediol and pregnanetriol by gas-liquid Chromatography. Amer. J. Obstet. Gynec., 103, 179-188.

Wray, P. M., and Russell, C. S. (1960). The value of the creatinine estimation as a gauge of the completeness of the 24-hour specimen. J. Obstet. Gynaec. Brit. Emp., 67, 623-626. 